\title{
Statistical diagnostic and correction of a chemistry-transport model for the prediction of total column ozone
}

\author{
S. Guillas ${ }^{1}$, G. C. Tiao $^{2}$, D. J. Wuebbles ${ }^{3}$, and A. Zubrow ${ }^{4}$ \\ ${ }^{1}$ School of Mathematics, Georgia Institute of Technology, Atlanta, Georgia, USA \\ ${ }^{2}$ Graduate School of Business, University of Chicago, Chicago, Illinois, USA \\ ${ }^{3}$ Department of Atmospheric Sciences, University of Illinois, Urbana, Illinois, USA \\ ${ }^{4}$ Center for Integrating Statistical and Environmental Science, University of Chicago, Chicago, Illinois, USA
}

Received: 14 September 2005 - Published in Atmos. Chem. Phys. Discuss.: 24 October 2005

Revised: 10 January 2006 - Accepted: 11 January 2006 - Published: 21 February 2006

\begin{abstract}
In this paper, we introduce a statistical method for examining and adjusting chemical-transport models. We illustrate the findings with total column ozone predictions, based on the University of Illinois at Urbana-Champaign 2D (UIUC 2-D) chemical-transport model of the global atmosphere.

We propose a general diagnostic procedure for the model outputs in total ozone over the latitudes ranging from $60^{\circ}$ South to $60^{\circ}$ North to see if the model captures some typical patterns in the data. The method proceeds in two steps to avoid possible collinearity issues. First, we regress the measurements given by a cohesive data set from the $\operatorname{SBUV}(/ 2)$ satellite system on the model outputs with an autoregressive noise component. Second, we regress the residuals of this first regression on the solar flux, the annual cycle, the Antarctic or Arctic Oscillation, and the Quasi Biennial Oscillation. If the coefficients from this second regression are statistically significant, then they mean that the model did not simulate properly the pattern associated with these factors. Systematic anomalies of the model are identified using data from 1979 to 1995 , and statistically corrected afterwards. The 19962003 validation sample confirms that the combined approach yields better predictions than the direct UIUC 2-D outputs.
\end{abstract}

\section{Introduction}

A lot of time and effort has been devoted to developing numerical chemistry-transport models in order to simulate and predict ozone changes. These models are based on the current understanding of the physical and chemical processes affecting the atmosphere, and have been primary tools in past studies to evaluate changes in stratospheric ozone resulting

Correspondence to: S. Guillas

(guillas@math.gatech.edu) from atmospheric emissions of halocarbons and other gases and aerosols. For a survey of these modeling tools, see WMO (2003). These numerical-physical models broadly simulate long-term changes in ozone. They do show some limitations, particularly in the treatment of the ozone "hole" processes in the Southern Hemisphere and in describing the observed asymmetry of the ozone loss after the major eruption of Mt. Pinatubo. As part of the validation process, the models need to be tested for their ability to replicate significant patterns of the short-term and long-term variations of ozone. In general, atmospheric models climatologies and biases are assessed and compared with observations, e.g. Hein et al. (2001); Austin et al. (2003); Dameris et al. (2005). Douglass et al. (1999) evaluated three 3-D chemistry transport models with scores by computing an index associated with the differences between model outputs and measurements. They tested the different components separately. Note that Fish and Burton (1997) and Considine et al. (1999) also assessed some of the uncertainties associated with predictions given by a chemistry-transport models. In this paper, we modify the UIUC 2-D total column model outputs based on the measurements and take into account inadequate representation of important features in the data and the influence of some explanatory variables including the solar flux, the Antarctic Oscillation (AAO), Arctic Oscillation (AO), and the Quasi Biennial Oscillation (QBO). We estimate the discrepancy between the model outputs and the measurements over the period January 1979 through December 1995 and then validate the statistically adjusted model with data over the period 1996-2003. We introduce a novel way to test, evaluate and improve numerical models relative to the traditional approaches, and present an general diagnostic technique based on a two-step regression scheme. The UIUC 2-D model illustrates the technique, and our approach can be applied to 3 -D model as well. We examine the results of these evaluations employing the UIUC 2-D model for the calculated

(C) 2006 Author(s). This work is licensed under a Creative Commons License. 
changes in ozone during 1996-2003 to demonstrate how statistical techniques can enable modelers to improve the confidence in model predictions. Note that this is not another layer of parametrisation, since we rely on observations to fix the model outputs. Indeed, we do not introduce a parameter that we have to tune empirically using scientific intuition, we perform a data-driven adjustment of the model. For true future scenarios, say over the 21st century, our method not only improves the seasonal representation (e.g. allowing for more accurate predictions for a particular month), but can also examine scenarios for given $\mathrm{QBO}$ and $\mathrm{AO}$ (e.g. allowing for a possible phase shift due to greenhouse-gas forcing in the AO, as explained in Shindell et al., 1999). It is possible that if feedbacks were to greatly alter the fundamental dynamics affecting the distribution of stratospheric ozone, then the approach used here would be inadequate for long term predictions. The approach we used may be useful for multi-decadal analyses, given that using a past learning period worked well for the recent decade: it is still better than just using original model.

The best correction would be to fix the model itself. However, modelers rely on few diagnostics to carry out corrections, and our technique yields new diagnostics that can help modelers. Furthermore, it is very difficult to change the model parametrisation in a way that it will directly affect a specific variation, and our statistical adjustment corrects the outputs in a data-driven way.

\section{The UIUC 2-D chemical-transport model}

The UIUC two-dimensional chemical-radiative-transport model is a zonally-averaged model of the chemistry and physics of the global atmosphere. The model is often used to study human related and natural forcings on the troposphere and stratosphere, but, because it is zonally-averaged, the analysis of tropospheric processes is limited. The model determines the atmospheric distributions of 78 chemically active atmospheric trace constituents. The model domain extends from pole to pole and from the ground to $84 \mathrm{~km}$. A grid element in the model represents $5^{\circ}$ of latitude and $1.5 \mathrm{~km}$ in log-pressure altitude. In addition to 56 photolytic reactions, the model incorporates 161 thermal reactions in the chemical mechanism, including heterogeneous reactions (e.g., see Wuebbles et al., 2001, or Wei et al., 2001). Reaction rates and photolysis cross-sections in the model are based on recommendations from the NASA's Chemical Kinetics Review Panel, e.g. DeMore et al. (1997); Sander et al. (2000).

The transport of chemical species is accomplished through advection, turbulent eddy transport, and convection. Transport of species in the model is self-consistently calculated using the predicted model ozone (and other radiatively important species) and seasonally varying climatological temperatures $(T)$, based on NCEP analyses. Model transport fields are evaluated by combining the zonal mean momentum equation and the thermodynamic equation into a form that, along with the thermal wind equation, yields a second order Poisson diagnostic equation for the residual mean meridional stream function. The right hand side of the stream function equation includes the net heating rate term and all wave forcings. The net heating rate is calculated knowing the temperature and chemical species distributions and includes latent heating. Planetary waves for wavenumbers 1 and 2 are included. Stratospheric values of $K_{y y}$ are calculated using the planetary wave dissipation rate and vorticity for both wave number 1 and 2. Values of $K_{z z}$ due to gravity waves are evaluated. Larger diffusion coefficients are assigned to the troposphere to mimic fast tropospheric mixing. The model uses a seasonally varying tropospheric $K_{y y}$. Convective transport in the model is based on the climatology of Langner et al. (1990).

The latest version of the UIUC 2-D model, labeled the 2002 version, has some key improvements incorporated in it. Major upgrades to the solution technique of residual mean meridional circulation (RMMC) and the treatments of atmospheric dynamics were made through better representation of the effects of planetary waves and a more accurate method for determining the RMMC (based on Choi, 1995; Choi and Youn, 2001). The treatment of planetary waves with wave numbers 1 and 2 have been updated with better data-based boundary topography and boundary winds. Latent heating and the sensible heat flux are specified based on more physically meaningful analyses (following Kim, 1999). An accurate and fast longwave radiation code for the height of surface to $60 \mathrm{~km}$ is adopted in the radiation part of the model. The improvements in the treatment of the infrared radiation and RMMC solution technique are discussed in Choi and Youn (2001). In the model, we derive the residual mean circulation using a fixed temperature field and u-bar. For our "current" atmosphere, we use the United Kingdom meteorological Office (UKMO) $T$ and u-bar fields to derive the circulation. The NCEP/NCAR $T$ fields are then used to get the trend in temperature from 1979-2002. The zonally averaged temperature and wind fields are specified based on the 6-year climatology of the United Kingdom meteorological Office (UKMO) reanalysis data. In addition, background diffusion coefficients, which cannot be explicitly obtained in the model, are also tuned for the "leaky pipe" model and the model barrier between tropics, mid-latitudes, and polar regions.

In the current version of the model the chemistry has been updated according to the NASA recommendations (Sander et al., 2000). This particularly affects the nitrogen oxide chemistry, the $\mathrm{N}_{2} \mathrm{O}_{5}$ and $\mathrm{ClONO}_{2}$ hydrolysis and several $\mathrm{HOCl}$ and $\mathrm{HCl}$ reactions. $\mathrm{HOBr}$ and $\mathrm{HOCl}$ cross-sections and the $\mathrm{O}_{3}$ photolysis quantum yields are updated as well.

All of these changes in the model have resulted in the improved representation of the distributions of age of air, which means better model transport in the "age of air concept" (Hall and Plumb, 1994; Hall et al., 1999). The upgraded components make the model mean age distribution closer 
to the observed features described in Models and Measurements II (Park et al., 1999). The mean age of greater than 5 years found at high latitudes in the mid- to upper stratosphere agrees much better with available data than the roughly 4 years found in the older version of the model used for the M\&M II analyses.

The UIUC 2-D CTM was used in a series of studies to evaluate the relative importance of various factors in determining how well the model represents observed trends in stratospheric ozone. For these studies, as outlined below, we considered the effects of changing emissions and concentrations of source gases, the effects of solar flux variations, the effects of volcanic eruptions through measured aerosol surface area densities, and the effects of changing stratospheric temperatures.

- The surface mixing ratios from WMO (2003) for all relevant source gases (e.g., halocarbons, methane, nitrous oxide, carbon monoxide) but updated using recent data from Climate Monitoring \& Diagnostics Laboratory (CMDL, using data on http://www.cmdl.noaa.gov/);

- The solar mid- and near-ultraviolet radiation (200 to $400 \mathrm{~nm}$ ) data from 1970 to 2002 (as updated by J. Lean, private communication, 2003, based on earlier analyses in Lean et al., 1997);

- Stratospheric aerosol surface area densities derived from extinction measurements by Stratospheric Aerosol and Gas Experiment (SAGE) II from 1981 to 2002 (as updated by L. Thomason, private communication, 2003, based on earlier analyses in Thomason et al., 1997);

- Tropospheric and stratospheric temperature data from 1980 to 2002 based on a combination of analyses for $1000 \mathrm{hPa}$ to $10 \mathrm{hPa}$ based on the National Center for Environmental Prediction/National Center for Atmospheric Research (NCEP/NCAR; http://dss.ucar.edu/ pub/reanalysis/) reanalysis, and the data from $10 \mathrm{hPa}$ to $0.5 \mathrm{hPa}$ based on NOAA Climate Predict Center (CPC; A. J. Miller, private communication, 2003) analyses.

The model describes the response to the solar flux and volcanic eruptions, but does not account for the Antarctic or Arctic Oscillation nor for the QBO. The model was run to 2005 using no $T$ trend and solar flux variations matching the last solar cycle. We then compared to ozone data through 2003.

\section{The data set}

The observed data set for ozone covers the period ranging from January 1979 to December 2003. This data set has been calibrated across multiple satellites data sources, and is averaged over the months, longitudes, and binned into $10^{\circ}$ latitude bands, forming monthly zonal means (Miller et al., 2002). The satellite observations are made by Solar Backscatter Ultraviolet Ozone Sensors (SBUV and SBUV/2). The overlap between the satellites have been used to estimate their relative biases and adjust all the data sets to the NOAA-9 SBUV/2 as the standard. We will make use of measurements for the $60^{\circ} \mathrm{S}-60^{\circ} \mathrm{N}$ latitudinal bands. Indeed, for latitudes lower than $60^{\circ} \mathrm{S}$ and higher than $60^{\circ} \mathrm{N}$, the instruments records are not complete because of the lack of solar ultraviolet radiation in their respective winters at those latitudes. In comparison to the Total Ozone Mapping Spectrometer (TOMS) zonal averages data set, the SBUVSBUV/2 data set has no major gaps. There were no TOMS measurements for parts of 1993 and 1994, for the whole year of 1995, and the first half of 1996. Fioletov et al. (2002) examined six data sets of monthly average zonal means of total column ozone, including ground-based measurements, and estimated past variations and trends. It turns out that groundbased measurements are inhomogeneous in terms of local ozone "climatology" due to the locations (especially longitude), the calibration, the type of instrument used (e.g. Dobson and Brewer instruments, filter ozonemeters), or an unclear systematic bias. Despite the coarser resolution of the calibrated SBUV-SBUV/2 data set and the lack of coverage for polar latitudes compared to the aformentioned data sets, we used the SBUV-SBUV/2 data set. Indeed, the lack of temporal gaps and the careful calibration are more important for the statistical study of the deficiencies of a CTM.

For solar flux, we used adjusted $2800 \mathrm{Mhz}$ flux data. They are corrected for the changing sun-earth distance (which contain fluctuations as large as 7\%). The Space Physics Interactive Data Resources http://spidr.ngdc.noaa.gov/spidr/index. html supplied monthly averages. The AAO, AO and QBO were provided by the NOAA Climate Prediction Center of the National Centers for Environmental Prediction (NCEP). These data can be found at http://www.cpc.ncep.noaa.gov/. The AAO and AO data are described in Thomson and Wallace (2000). The QBO data are given by the Climate Data Assimilation System (CDAS) reanalysis data at the National Oceanic and Atmospheric Administration's Climate Prediction Center http://www.cpc.ncep.noaa.gov/data/indices/ and are the zonally averaged winds at $50 \mathrm{hPa}$ over the equator. The QBO data is lagged two months per $10^{\circ}$ of latitude, based on Zerefos et al. (1992). Since the QBO index was not available before January 1979, we calibrated the QBO index with available Singapore winds data at $50 \mathrm{hPa}$ and retrieved an approximate zonally averaged winds for 1978. Furthermore, we added two seasonally dependent QBO's by multiplying the QBO index by either $\sin (2 \pi t / 12)$ or $\cos (2 \pi t / 12)$ - where $t$ is time in months - to account for the seasonal dependence of total column ozone on the QBO. The QBO could be more adequately accounted for by using one more Fourier pair. However, for model parsimony, and thus to get smaller uncertainties in the parameters estimation, we resorted to only one Fourier pair. 
$-60$
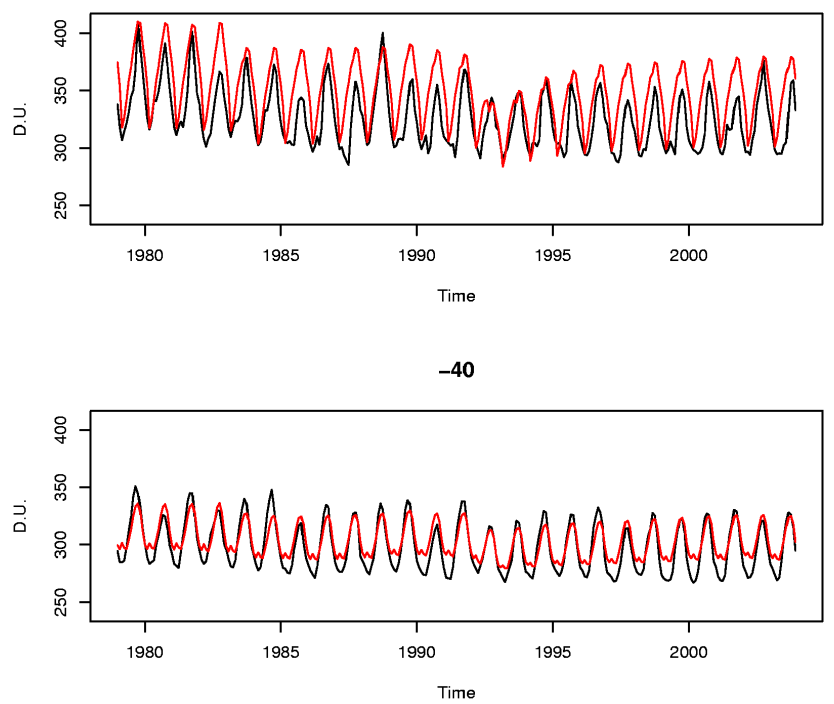

$-20$

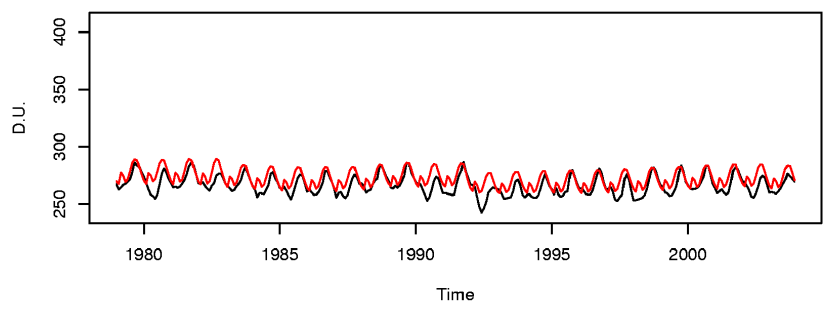

$-50$
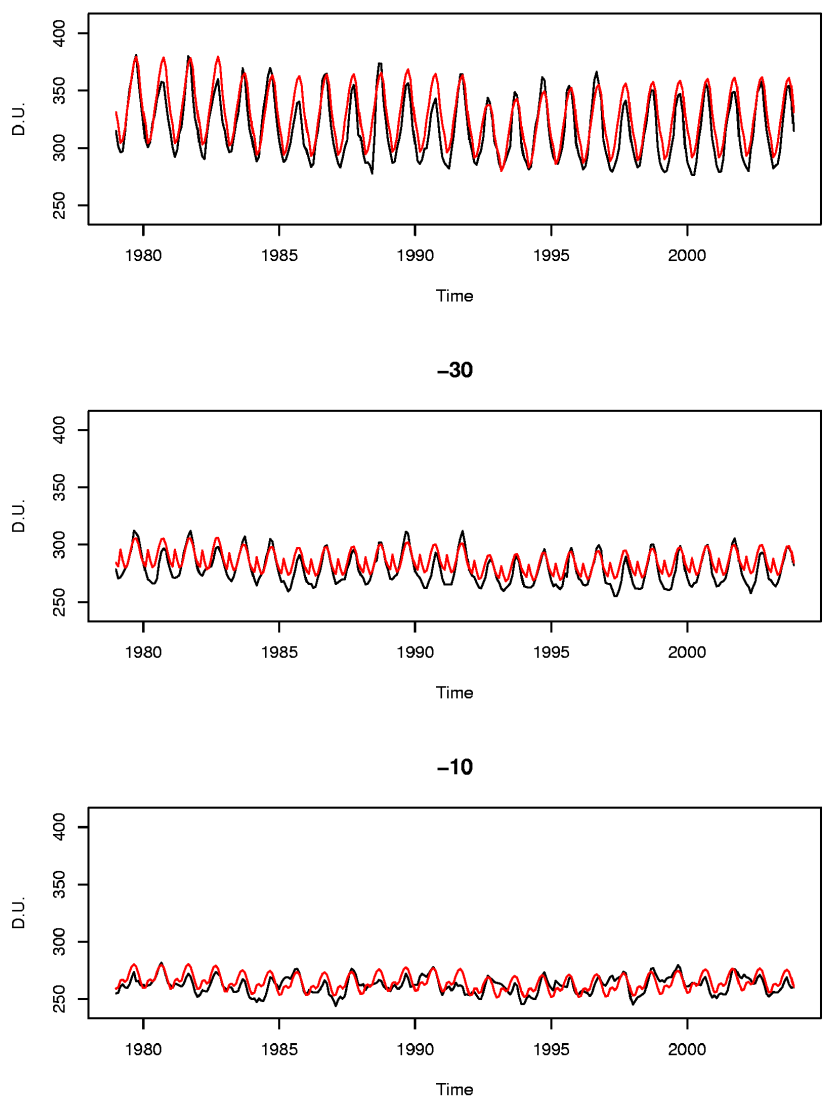

Fig. 1. Time series of monthly measurements (black) and model outputs (red) over the period January 1979 to December 2003 . Latitude bands: $60^{\circ}-50^{\circ} \mathrm{S}$ to $10^{\circ}-0^{\circ} \mathrm{S}$.

\section{Diagnostics}

A natural approach to evaluate a numerical model of the atmosphere is to gauge specific features. Total column ozone at any given location depends on many factors, including the solar flux, the AAO/AO and the QBO. As shown in Fig. 1 which displays the total column ozone measurements (in black) and the UIUC 2-D model outputs (in red) for six latitude bands in the Southern hemisphere, a noticeable drawback of the current UIUC 2-D model is the discrepancy in the seasonal representation of total ozone. Figure 5 (left panel) shows more clearly the differences for the Northern midlatitudes. The situation is similar for the Northern hemisphere, as shown in Fig. 2. As a result, we are particularly interested in examining the monthly patterns. Moreover, we want to determine whether the solar cycle is adequately treated in the model calculations, and whether it may be possible to assess the $\mathrm{AAO} / \mathrm{AO}$ and the $\mathrm{QBO}$ influences which are not present in the UIUC 2-D model.

Douglass et al. (1999) carried out several tests to assess three 3-D chemistry transport models. For instance, when examining the modeled temperatures, a criterion based on differences between the National Centers for Environmental Prediction (NCEP) analyses and model outputs was introduced. The grade for a specific latitude band at $50 \mathrm{hPa}$ is given by

grade $=1-\frac{1}{12} \sum_{i=1}^{12} \frac{\left|T_{i}^{\mathrm{MODEL}}-T_{i}^{\mathrm{NCEP}}\right|}{3 \sigma_{i}^{\mathrm{NCEP}}}$,

where $T$ is the monthly mean temperature, $i$ is the month, $\sigma_{i}^{\text {NCEP }}$ is the NCEP temperature's standard deviation for month $i$. Other tests were introduced for various physical processes of interest. These tests are very useful for the modelers, since the models can be changed based on the results of the tests. Tests results for specific processes (e.g. associated with transport or chemistry) help understand the model behavior. However, for the case of total column ozone, these tests ought to be combined in order to take into account the interactions between the processes. In this paper, our procedure aims at weighting the various deficiencies with respect to their impact on ozone. Accordingly, the diagnosticf we present here can be used to directly correct the model outputs. 
o

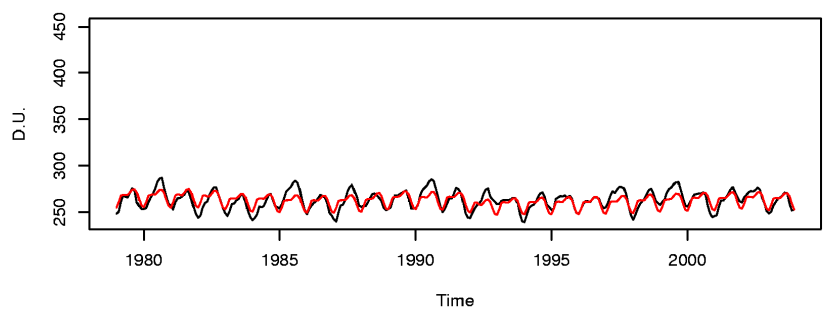

20

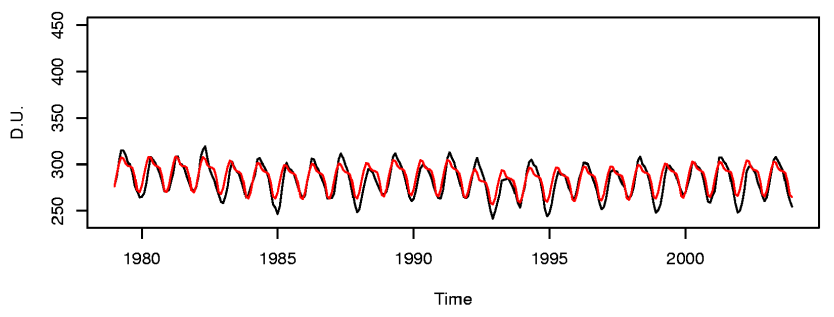

40

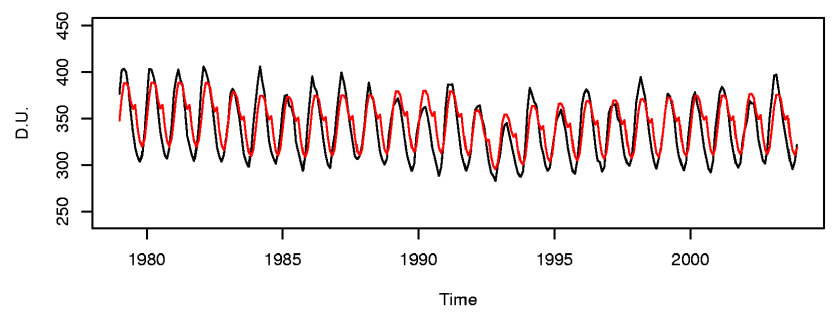

10

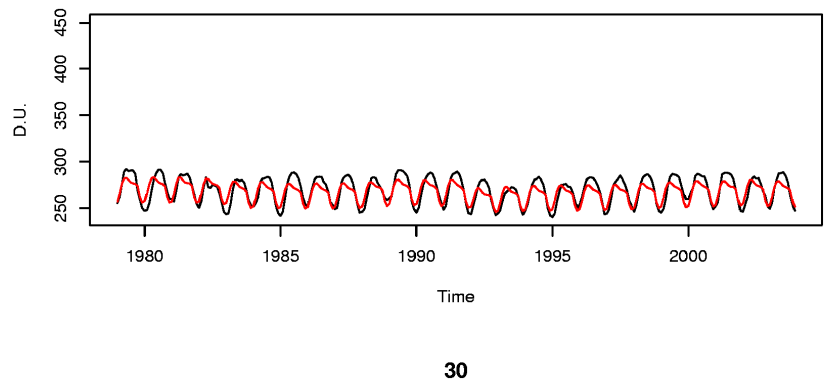

30

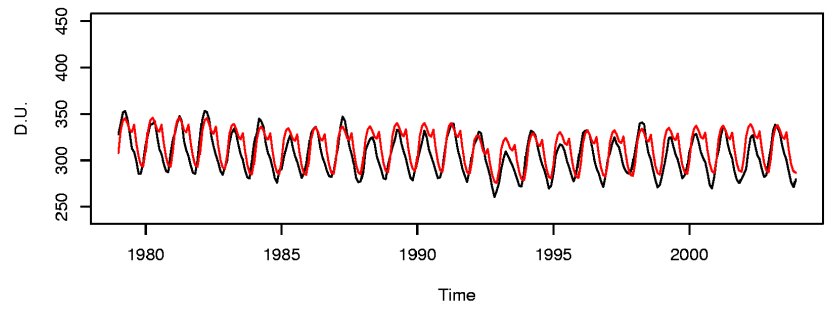

50

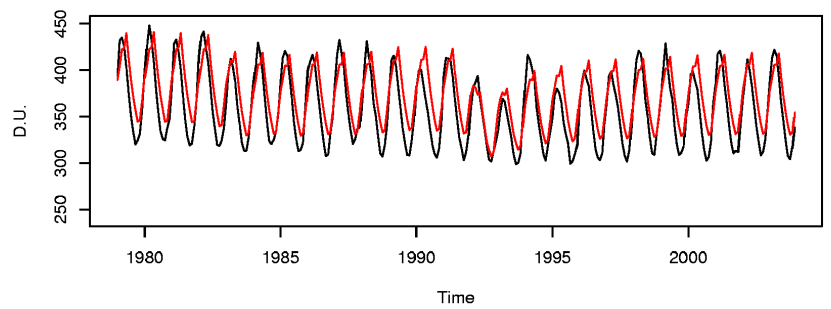

Fig. 2. Time series of monthly measurements (black) and model outputs (red) over the period January 1979 to December 2003 . Latitude bands: $0^{\circ}-10^{\circ} \mathrm{N}$ to $50^{\circ}-60^{\circ} \mathrm{N}$.

Our approach is based on two first-order approximations. First, we suppose that the measurements are approximately linearly related to the model outputs. Thus, we tentatively assume that a level shift and a scale factor explains most of the discrepancy between the model and the measurements. To account for unexplained short-term dynamic geophysical phenomena, we use an autoregressive noise, e.g. Reinsel et al. (1981); Tiao et al. (1990); Weatherhead et al. (1998) when comparing the model outputs and the measurements. Secondly, we examine the residuals from this first linear regression. If the model is adequately simulating ozone behavior (up to a level shift and a scale factor), then there is no relevant information in these residuals. On the other hand, if the model does not properly represent the influence of an explanatory variable (e.g. an oscillation or a seasonal variation), then the residuals should exhibit a signal of the discrepancy with respect to this variable. Our second first-order approximation is thus a linear relation between the residuals from the first regression and the explanatory variables.

Note that a purely empirical statistical method might skip the intermediate step where the model is involved and directly relate the measurements to the explanatory variables.
By doing so, only one, but strong, first-order approximation is assumed. In the case of a non-linear influence of a particular variable or a combination of variables (e.g. aerosols and solar cycle, Solomon et al., 1996) this assumption can be violated. Using a chemistry-transport model in the two steps approach, only in the second step the model inadequacies are assumed to be approximately linearly related to the explanatory variables. This seems more reasonable.

We only accounted for the seasonality in the QBO coefficient, since the other influences do not depend as strongly on the season, and we want to set up a parsimonious model. We dealt with seasonality using indicators of each month, because, as shown in Fig. 2, the seasonal cycle in the model is difficult to represent in terms of sines and cosines: There are "kinks" seemingly due to model "swings" in latitudes. Randel and Cobb (1994) proposed another alternative, by removing the seasonal cycle in total column ozone and lower stratospheric temperatures, and then observe the strong association. However, this method, in addition to require twice as many seasonal parameters, can not be used to evaluate seasonal deficiencies of the model. 
Table 1. Coefficients estimates from the first regression of the measurements on the model outputs, and Residual Standard Error. January 1979 to December 2003. A perfect match between the model and the measurements would yield $c=0$ and $a=1$ (Standard errors in parentheses).

\begin{tabular}{ccccc}
\hline Latitude & $\mathrm{c}$ & $\mathrm{a}$ & $\rho$ & RSE \\
\hline $60-50^{\circ} \mathrm{S}$ & $\mathbf{1 0 0 . 0}(13.8)$ & $\mathbf{0 . 6 4}(0.04)$ & $0.70(0.04)$ & 10.0 \\
$50-40^{\circ} \mathrm{S}$ & $-10.5(10.9)$ & $1.00(0.03)$ & $0.72(0.04)$ & 6.8 \\
$40-30^{\circ} \mathrm{S}$ & $\mathbf{- 7 2 . 4}(13.1)$ & $\mathbf{1 . 2 2}(0.04)$ & $0.77(0.04)$ & 5.2 \\
$30-20^{\circ} \mathrm{S}$ & $\mathbf{8 3 . 9}(13.9)$ & $\mathbf{0 . 6 8}(0.05)$ & $0.80(0.04)$ & 5.4 \\
$20-10^{\circ} \mathrm{S}$ & $\mathbf{1 1 5 . 5}(11.9)$ & $\mathbf{0 . 5 5}(0.04)$ & $0.79(0.04)$ & 3.6 \\
$10-0^{\circ} \mathrm{S}$ & $\mathbf{8 8 . 6}(10.3)$ & $\mathbf{0 . 6 6}(0.04)$ & $0.87(0.03)$ & 2.8 \\
$0-10^{\circ} \mathrm{N}$ & $4.1(11.8)$ & $0.99(0.04)$ & $0.87(0.03)$ & 3.1 \\
$10-20^{\circ} \mathrm{N}$ & $-15.0(13.0)$ & $1.06(0.05)$ & $0.81(0.04)$ & 4.4 \\
$20-30^{\circ} \mathrm{N}$ & $7.1(11.1)$ & $0.96(0.04)$ & $0.81(0.03)$ & 4.9 \\
$30-40^{\circ} \mathrm{N}$ & $\mathbf{9 9 . 0}(14.0)$ & $\mathbf{0 . 6 6}(0.04)$ & $0.82(0.04)$ & 7.2 \\
$40-50^{\circ} \mathrm{N}$ & $40.0(27.0)$ & $0.87(0.08)$ & $0.81(0.05)$ & 11.3 \\
$50-60^{\circ} \mathrm{N}$ & $-8.4(25.0)$ & $0.99(0.07)$ & $0.77(0.06)$ & 12.2 \\
\hline
\end{tabular}

Carrying out a linear regression of the residuals on the relevant patterns (indicators of the months and explanatory variables) enables us to examine the coefficients associated with these factors. If the coefficients are not statistically significant then the model has captured the influence of these factors; if the coefficients are significant, we can give a measure of the anomaly. More precisely, our proposed two steps are the following:

- Step 1. Regress the measurements on model outputs, with an autoregressive model of order one $(\mathrm{AR}(1))$ component. Denoting by $O(t)$ the measured monthly total column ozone, and by $M(t)$ the model outputs, the regression equation is

$O(t)=c+a M(t)+N_{t}$,

where $N_{t}$ is $\mathrm{AR}(1)$, i.e. $N_{t}=\rho N_{t-1}+\epsilon_{t}$ with $\left(\epsilon_{t}\right)$ a sequence of independent identically distributed Normal random variables (white noise) with common variance $\sigma_{\epsilon}^{2}$.

- Step 2. Regress the estimated residuals $\hat{\epsilon}_{t}$ from the first step regression on the indicators of the months, possible trends, and the explanatory variables to see whether or not the model captures these features. Specifically, we denote by $m_{i}(t)$, i=January, February,..., December the indicators of the months throughout time such that $m_{i}(t)=0$ except for month $t=i$ where $m_{i}(t)=1$. Also, denote by $s(t)$ the monthly solar flux, $a o(t)$ either the AAO index (Southern hemisphere) or the AO index (Northern hemisphere), $q b o(t)$ the QBO index, $q b o s(t)$ the QBO index multiplied by $\sin (2 \pi t / 12)$, and $q b o c(t)$ the $\mathrm{QBO}$ index multiplied by $\cos (2 \pi t / 12)$, the linear trend indicator $t / 12$, and the contrasted slopechange recovery indicator $r(t)$ which is equal to 0 before $t_{0}=$ January 1996 and $t-t_{0}$ after January 1996 (Reinsel, 2002). Thus, we examine the regression:

$$
\begin{aligned}
\hat{\epsilon}_{t}= & \sum_{i=1}^{12} \alpha_{i} m_{i}(t)+b s(t)+\omega_{1} t / 12+\omega_{2} r(t) \\
& +c_{a o} a o(t)+c_{q b o} q b o(t)+c_{q b o s} q b o s(t) \\
& +c_{q b o c} q b o c(t)+\epsilon_{t}^{\prime}
\end{aligned}
$$

where $\left(\epsilon_{t}^{\prime}\right)$ is a white noise.

Each latitude band is treated as independent and the regression on the 12 latitude bands provide 12 sets of values for the parameters $c$ and $a$. The standard errors correspond to the least square error from the 300 data points for each band.

Table 1 displays the values of $a$ and $c$ in Eq. (1) over the period 1979-2003 for the 12 10-degree latitude bands from $50-60^{\circ} \mathrm{S}$ to $50-60^{\circ} \mathrm{N}$. If the model adequately describes the evolution of ozone, the constant $\mathrm{c}$ would be close to 0 and the regression coefficient $a$ would be close to 1 . However, many of those numbers are statistically different from 0 or 1 , respectively, suggesting possible improvements are needed.

The $\alpha_{i}$ 's are summarized in Fig. 3 for the UIUC 2-D model over 1979-2003. The standard errors (not shown in Fig. 3), which depend on the latitude and the month considered, are usually less than $3 \mathrm{DU}$ at the midlatitudes and much less near the equator. Such small uncertainties are due to the fact that we accounted for the circulation through the QBO and the $\mathrm{AO}$. Indeed, the $\mathrm{QBO}$ and $\mathrm{AO}$ are no longer confounding factors that could potentially increase the standard errors of the monthly deficiencies. For the entire time period, we can observe obvious inadequacy in the seasonal representation of the model. For example, for $50-60^{\circ} \mathrm{N}$, the shifted and rescaled model (first regression) underestimates total column ozone in the Autumn and Winter seasons (blue cells), but overestimates ozone by an average of 20 to $30 \mathrm{DU}$ in the month of May (red cell). The circulation in the real atmosphere changes from year to year. Hence, the monthly differences between model outputs and observations are not relatively constant. The monthly anomalies computed in our study are not the mere monthly differences, but the monthly differences acounting for the circulation through the QBO and the AO. The monthly anomalies are relatively constant because the misrepresentation of the seasonal variation stays relatively constant with time, when accounting for year to year variations of the circulation.

Table 2 displays the coefficients other than the $\alpha_{i}$ 's from Eq. (2) over the period 1979-2003. None of the solar cycle or the linear trend and slope change coefficients are statistically significant (with the 2 standard errors rule). Hence, the UIUC 2-D model is adequately simulating the solar influence and the long-term trends. For other geophysical variations (AAO, $\mathrm{AO}$ and $\mathrm{QBO}$ ) that are not included in the 


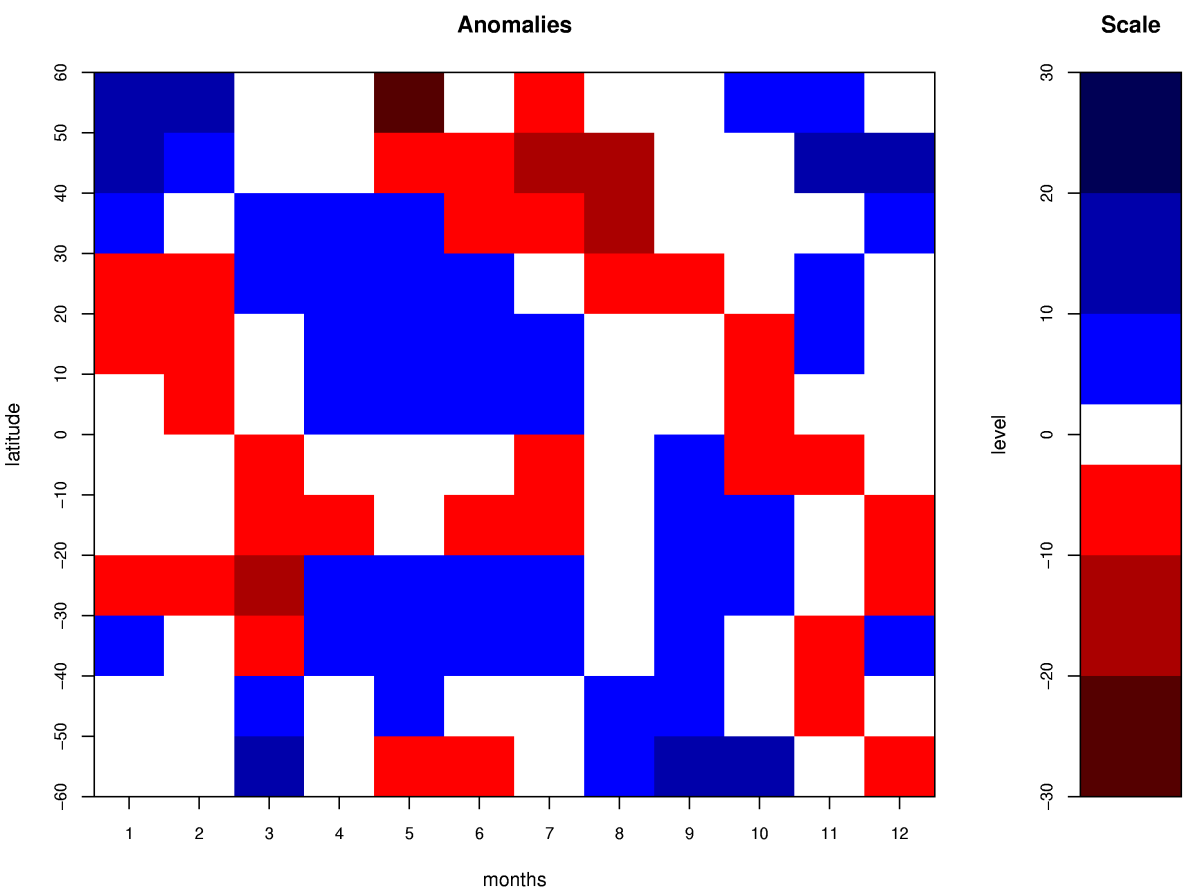

Fig. 3. Monthly anomalies (i.e. indicators of the months coefficients estimates from the second regression), 1979-2003 for the UIUC 2-D model, Dobson Units. White: not significant (coefficient estimate smaller than 2 standard errors). Blue: the model underestimates by more than 2 standard errors. Red: the model overestimates by more than 2 standard errors.

Table 2. Coefficients estimates of the second regression (Eq. 2) based on regressing the residuals from the first regression on the solar flux ( $b$ in DU per 100 flux), the linear downward trend ( $\omega_{1}$ in DU per decade), the contrasted recovery ( $\left(\omega_{2}\right.$ in DU per decade), the AAO (South) or the AO (North) ( $c_{a o}$ per 10 units of either $700 \mathrm{hPa}$ height anomalies poleward of $20^{\circ} \mathrm{S}$ or $1000 \mathrm{hPa}$ height anomalies poleward of $20^{\circ} \mathrm{N}$ on their respective loading patterns), the QBO $\left(c_{q b o}\right.$ per 10 units of $50 \mathrm{hPa}$ zonal wind index) with its sine $\left(c_{q b o s}\right)$ and cosine $\left(c_{q b o c}\right)$ multiples, and the indicators of the months (not displayed here: see Fig. 6a). January 1979 to December 2003. An insignificant coefficient means no model anomaly for the related regressor (Standard errors in parentheses).

\begin{tabular}{lccccccc}
\hline Latitude & $b$ (solar) & $\omega_{1}$ (trend) & $\omega_{2}$ (recovery) & $c_{a o}$ & $c_{q b o}$ & $c_{q b o s}$ & $c_{q b o c}$ \\
\hline $60-50^{\circ} \mathrm{S}$ & $0.14(0.80)$ & $-0.75(0.89)$ & $-0.09(0.23)$ & $-0.73(0.38)$ & $-0.04(0.61)$ & $-1.13(0.83)$ & $1.29(0.80)$ \\
$50-40^{\circ} \mathrm{S}$ & $-0.73(0.58)$ & $0.58(0.65)$ & $-0.24(0.17)$ & $-\mathbf{1 . 2 7}(0.28)$ & $\mathbf{1 . 2 5}(0.44)$ & $-\mathbf{1 . 4 0}(0.57)$ & $-\mathbf{1 . 7 1}(0.62)$ \\
$40-30^{\circ} \mathrm{S}$ & $-0.62(0.37)$ & $0.15(0.41)$ & $-0.15(0.11)$ & $-0.17(0.18)$ & $\mathbf{1 . 5 7}(0.28)$ & $-\mathbf{1 . 3 7}(0.39)$ & $-\mathbf{2 . 1 3}(0.37)$ \\
$30-20^{\circ} \mathrm{S}$ & $0.25(0.30)$ & $-0.43(0.33)$ & $0.02(0.09)$ & $0.12(0.14)$ & $\mathbf{1 . 5 2}(0.22)$ & $-0.61(0.31)$ & $-\mathbf{2 . 2 3}(0.30)$ \\
$20-10^{\circ} \mathrm{S}$ & $0.35(0.25)$ & $-0.30(0.28)$ & $0.04(0.07)$ & $0.21(0.12)$ & $\mathbf{0 . 8 0}(0.19)$ & $-0.17(0.25)$ & $-\mathbf{1 . 8 9}(0.27)$ \\
$10-0^{\circ} \mathrm{S}$ & $0.11(0.26)$ & $0.25(0.29)$ & $-0.04(0.08)$ & $0.02(0.12)$ & $\mathbf{- 1 . 4 2}(0.20)$ & $0.22(0.27)$ & $-0.34(0.26)$ \\
$0-10^{\circ} \mathrm{N}$ & $-0.11(0.27)$ & $0.36(0.30)$ & $-0.06(0.08)$ & $0.21(0.13)$ & $\mathbf{- 1 . 4 5}(0.20)$ & $-0.38(0.28)$ & $-0.23(0.26)$ \\
$10-20^{\circ} \mathrm{N}$ & $-0.45(0.29)$ & $0.13(0.32)$ & $0.00(0.08)$ & $\mathbf{0 . 4 8}(0.14)$ & $\mathbf{0 . 5 4}(0.21)$ & $-0.03(0.28)$ & $\mathbf{1 . 3 7}(0.30)$ \\
$20-30^{\circ} \mathrm{N}$ & $-0.25(0.33)$ & $-0.13(0.36)$ & $-0.05(0.10)$ & $\mathbf{0 . 4 5}(0.16)$ & $\mathbf{1 . 1 6}(0.24)$ & $0.12(0.33)$ & $\mathbf{2 . 2 5}(0.32)$ \\
$30-40^{\circ} \mathrm{N}$ & $-0.01(0.45)$ & $-0.52(0.49)$ & $-0.03(0.13)$ & $-\mathbf{0 . 5 5}(0.22)$ & $\mathbf{0 . 6 6}(0.33)$ & $0.32(0.45)$ & $\mathbf{2 . 5 7}(0.44)$ \\
$40-50^{\circ} \mathrm{N}$ & $-0.10(0.59)$ & $-0.07(0.66)$ & $-0.02(0.17)$ & $\mathbf{- 2 . 7 1}(0.29)$ & $-0.11(0.44)$ & $-0.14(0.57)$ & $0.76(0.62)$ \\
$50-60^{\circ} \mathrm{N}$ & $-0.73(0.76)$ & $0.02(0.84)$ & $-0.03(0.22)$ & $\mathbf{- 2 . 0 3}(0.38)$ & $0.80(0.57)$ & $0.96(0.77)$ & $1.10(0.75)$ \\
\hline
\end{tabular}

UIUC 2-D model, many anomalies do appear. The $c_{a o}$ 's are significant from $10^{\circ} \mathrm{N}$ to $60^{\circ} \mathrm{N}$. For the Southern hemisphere, the coefficient is significant only for $50-40^{\circ} \mathrm{S}$. This asymmetry of the anomalies associated with these oscillations might be explained by the limited understanding of the dynamics in the Southern hemisphere for midlatitudes. The $c_{q b o}, c_{q b o s}, c_{q b o c}$ are significant for all latitudes except for $60-50^{\circ} \mathrm{S}, 40-50^{\circ} \mathrm{N}$, and $50-60^{\circ} \mathrm{N}$. Either these latitudes do not show a statistically strong enough connection between the QBO and the ozone or our representation of the QBO should be improved for these high latitudes. 
$60-50 S$

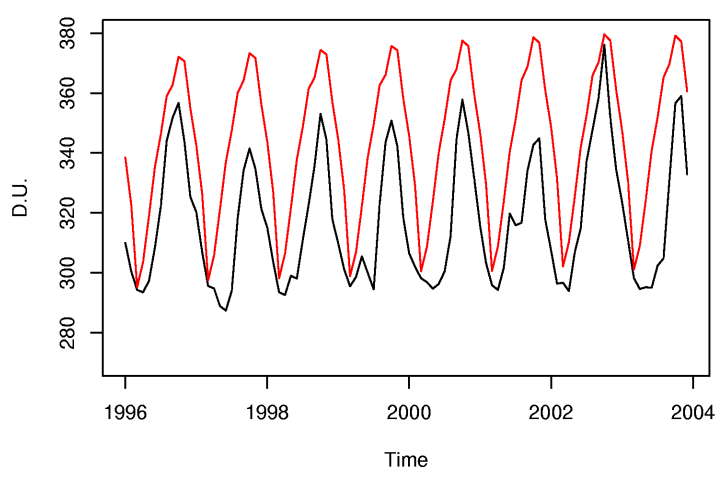

50-40S

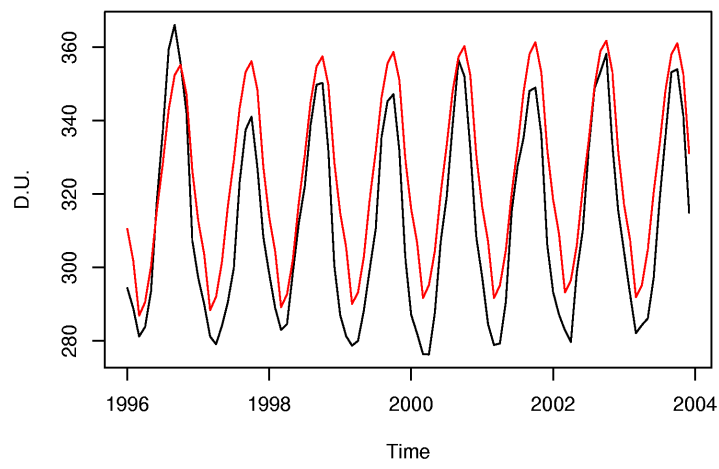

$60-50 S$

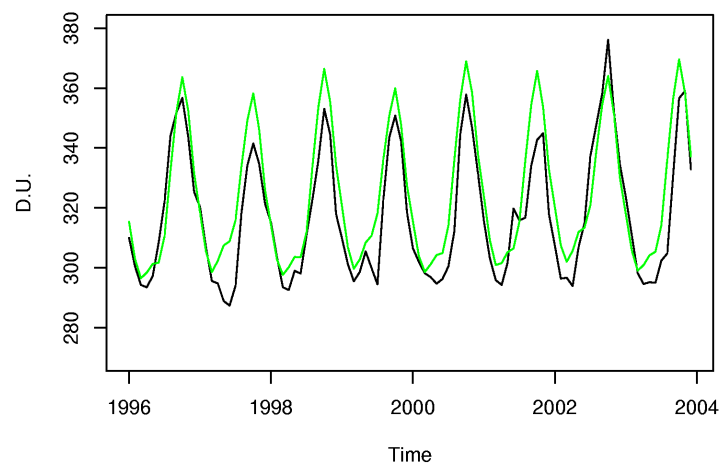

50-40S

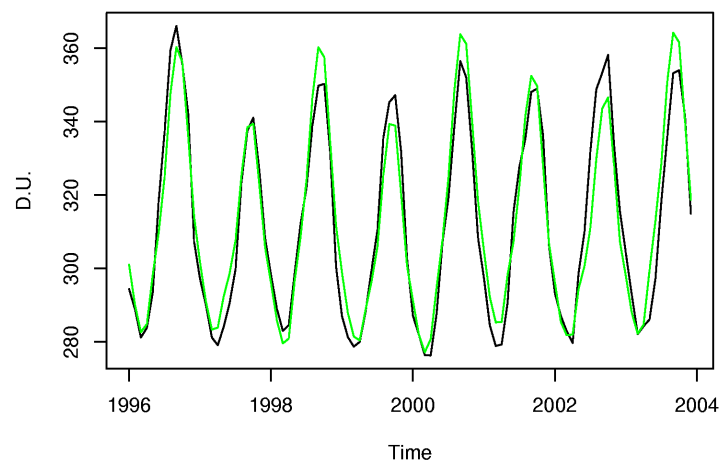

Fig. 4. Time series of measurements (black), UIUC 2-D model outputs (red), and statistically adjusted UIUC 2-D model outputs (green). In Dobson Units, $1996-2003$, for latitude bands $60^{\circ}-50^{\circ} \mathrm{S}$ and $40^{\circ}-50^{\circ} \mathrm{S}$.

Table 3. Coefficients estimates from the first regression of the measurements on the model outputs, and Residual Standard Error over the period January 1979 to December 1995. A perfect match between the model and the measurements would yield $c=0$ and $a=1$. (Standard errors in parentheses.)

\begin{tabular}{lcccc}
\hline Latitude & $\mathrm{c}$ & $\mathrm{a}$ & $\rho$ & $\mathrm{RSE}$ \\
\hline $60-50^{\circ} \mathrm{S}$ & $\mathbf{9 9 . 1 ( 1 6 . 9 )}$ & $\mathbf{0 . 6 5}(0.05)$ & $0.70(0.05)$ & 10.4 \\
$50-40^{\circ} \mathrm{S}$ & $-1.9(13.8)$ & $0.98(0.04)$ & $0.71(0.05)$ & 7.3 \\
$40-30^{\circ} \mathrm{S}$ & $\mathbf{- 5 9 . 4 ( 1 6 . 6 )}$ & $\mathbf{1 . 1 8}(0.05)$ & $0.77(0.05)$ & 5.4 \\
$30-20^{\circ} \mathrm{S}$ & $\mathbf{9 5 . 2}(16.7)$ & $\mathbf{0 . 6 5}(0.06)$ & $0.80(0.04)$ & 5.4 \\
$20-10^{\circ} \mathrm{S}$ & $\mathbf{1 2 1 . 8}(14.3)$ & $\mathbf{0 . 5 3}(0.05)$ & $0.80(0.04)$ & 3.6 \\
$10-0^{\circ} \mathrm{S}$ & $\mathbf{8 6 . 0}(12.4)$ & $\mathbf{0 . 6 6}(0.05)$ & $0.85(0.04)$ & 2.7 \\
$0-10^{\circ} \mathrm{N}$ & $-0.6(15.1)$ & $1.00(0.06)$ & $0.87(0.03)$ & 3.3 \\
$10-20^{\circ} \mathrm{N}$ & $-11.7(16.3)$ & $1.05(0.06)$ & $0.81(0.04)$ & 4.5 \\
$20-30^{\circ} \mathrm{N}$ & $10.7(13.5)$ & $0.95(0.05)$ & $0.80(0.04)$ & 4.9 \\
$30-40^{\circ} \mathrm{N}$ & $\mathbf{9 8 . 7}(17.4)$ & $\mathbf{0 . 6 6}(0.05)$ & $0.82(0.05)$ & 7.3 \\
$40-50^{\circ} \mathrm{N}$ & $15.7(30.1)$ & $0.94(0.09)$ & $0.78(0.06)$ & 11.4 \\
$50-60^{\circ} \mathrm{N}$ & $-2.5(29.6)$ & $0.97(0.08)$ & $0.77(0.06)$ & 12.5 \\
\hline
\end{tabular}

We remark here that an alternative to this two-step methodology would be to carry out only one regression with model outputs and all the components included in the second regression. This raises a statistical problem. Specifically, near collinearities between the regressors, specifically the model outputs and the indicators of the months as well as the solar flux will empirically appear and deteriorate the estimation, e.g. see Stewart (1987) for a theoretical explanation. For all latitudes, the coefficients associated with the indicators of the months are highly not significant when running a one-step regression (our results show that T-values usually smaller than 0.2 instead of greater then 2 for significance), and we can not detect seasonal misrepresentations in the model. Thus, the one-step approach does not yield a good diagnostic.

\section{Estimation and validation}

To estimate discrepancies with respect to the specific variables and test their validities for prediction, we divide the data into two segments: 1979-1995 for estimation and 19962003 for validation. Tables 3 and 4 display the first step regression for these two periods, showing results broadly similar to those in Table 1 indicating that the discrepancies remain stable over time. 
$40-50 \mathrm{~N}$

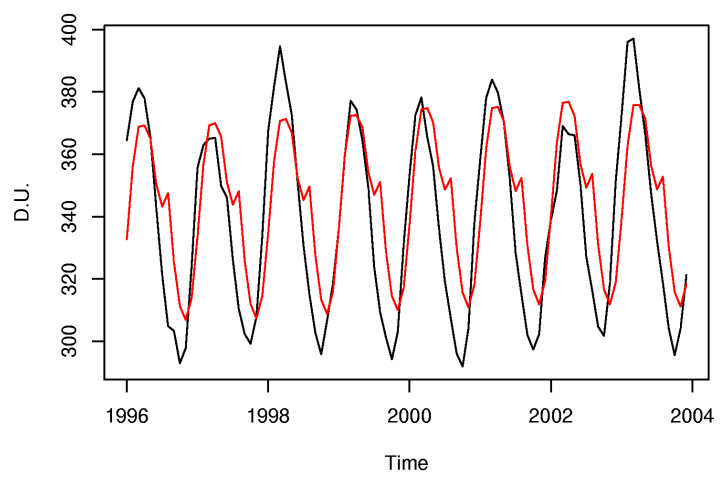

$50-60 N$

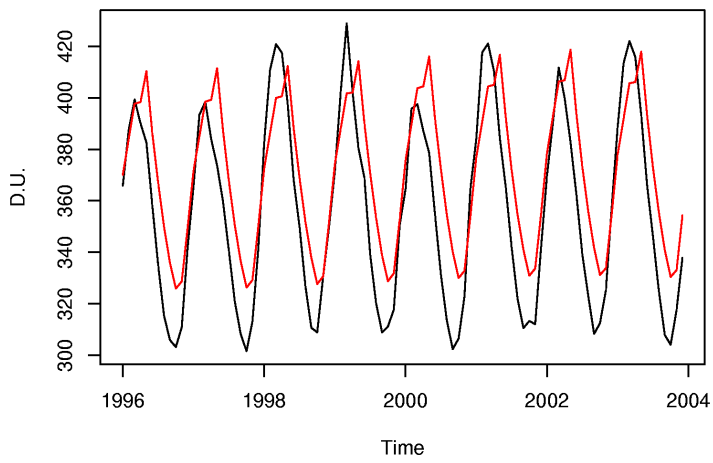

$40-50 \mathrm{~N}$

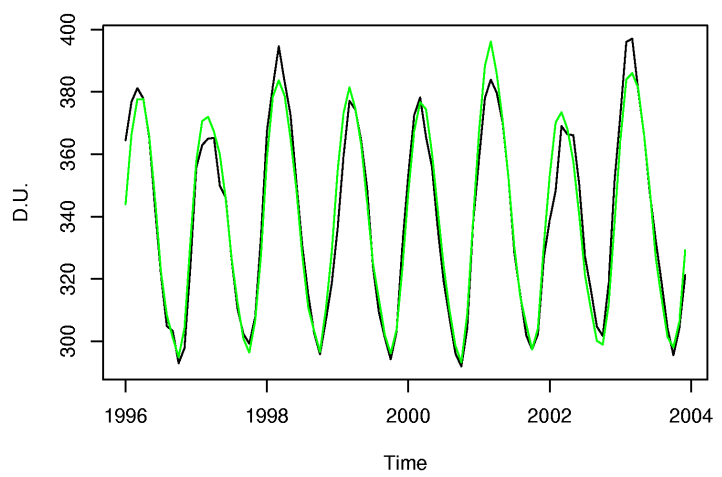

$50-60 \mathrm{~N}$

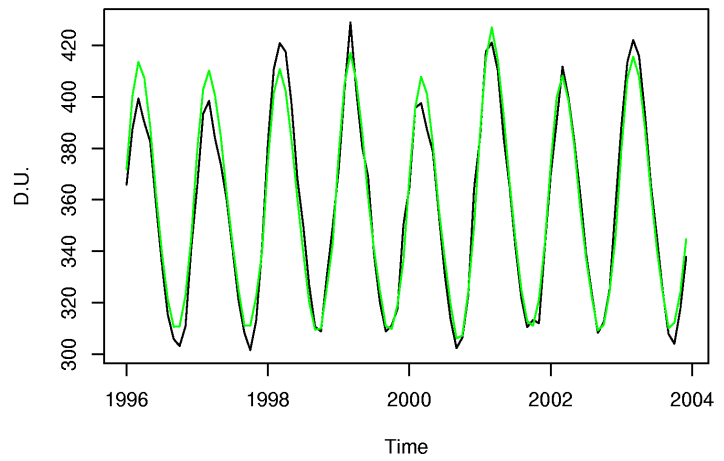

Fig. 5. Time series of measurements (black), UIUC 2-D model outputs (red), and statistically adjusted UIUC 2-D model outputs (green). In Dobson Units, $1996-2003$, for latitude bands $40^{\circ}-50^{\circ} \mathrm{N}$ and $50^{\circ}-60^{\circ} \mathrm{N}$.

We now propose a correction of the UIUC 2-D model using the two-step results. First, we estimate the coefficients using the two-step procedure for data from 19791995. The results for the first regression are given earlier in Table 3, and those for the second regression in Table 5 (which are broadly similar to Table 2). Let us denote by $\hat{c}, \hat{a}, \hat{b}, \hat{\alpha}_{i}, \hat{\beta}_{i} \hat{c}_{a o}, \hat{c}_{q b o}, \hat{c}_{q b o s}, \hat{c}_{q b o c}$ the estimates of the coefficients (see Eqs. 1 and 2). Note that for the second regression over the time period 1979-1995 the trend recovery term $r(t)$ is not present, and the trend estimates of $\omega$ are also dropped because all of them are highly insignificant. Denote by $\hat{\rho}$ the estimate of the autocorrelation $\rho$ in the first regression, and $\hat{\epsilon}_{t}^{\prime}$ the estimated residual noise in the second regression. It is readily seen that the adjusted model output $\tilde{M}(t)$ corresponding to the model outputs $M(t)$ for the time period 1996-2003, for a specific latitude band, will then be given by:

$\tilde{M}(t)=\hat{c}+\hat{a} M(t)+\hat{N}_{t}^{\prime}$,

where $M(t)$ is the model output for the second period 19962003 and

$\hat{N}_{t}^{\prime}=\hat{\rho} \hat{N}_{t-1}^{\prime}+\hat{b} s(t)+\sum_{i=1}^{12} \hat{\alpha}_{i} m_{i}(t)+\hat{c}_{a o} a o(t)$

$$
+\hat{c}_{q b o} q b o(t)+\hat{c}_{q b o s} q b o s(t)+\hat{c}_{q b o c} q b o c(t)
$$

Table 5 shows that the linear trend and the solar flux coefficients were never deemed as statistically significant in the second step regression. This proves that the model captured most of the pattern induced by the solar flux effect on stratospheric ozone, and demonstrates an ability at simulating properly the long term trend. Again, we have not included the linear trend estimate $\hat{\omega}_{1}$ in the correction since it was never significant. However, on a shorter scale of less than a decade, some variations are not properly taken into account. Indeed, the AAO/AO coefficients are often significant (especially in the Northern hemisphere), as well as the QBO coefficients. Note that the UIUC 2-D model does not include the $\mathrm{AAO} / \mathrm{AO}$ and $\mathrm{QBO}$ and therefore it is logical that significant anomalies arise. Only for $60-50^{\circ} \mathrm{S}$, our method did not detect any significant coefficient among the AAO/AO and QBO's, stressing the difficulty in the treatment of the Antarctic dynamic.

For the second or validation period, 1996-2003, the modified or adjusted model for the measurements is given by the regression equation

$O(t)=c+a \tilde{M}(t)+N_{t}$, 

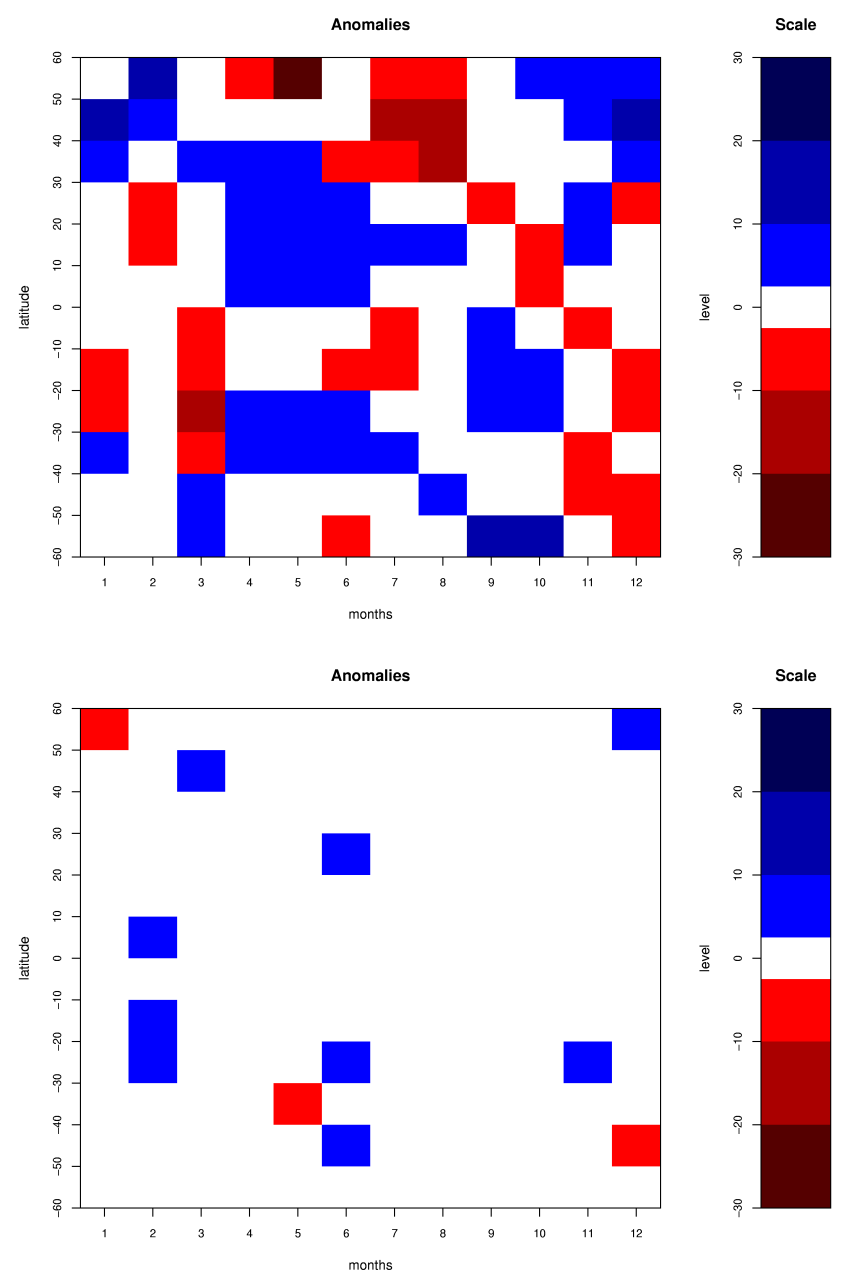

Fig. 6. Monthly anomalies (i.e. indicators of the months coefficients estimates form the second regression), 1996-2003 for (a): the UIUC 2-D model, (b): the statistically adjusted UIUC 2-D model. White: not significant (coefficient estimate smaller than 2 standard errors). Blue: the model underestimates by more than 2 standard errors. Red: the model overestimates by more than 2 standard errors.

where $N_{t}$ is $\mathrm{AR}(1)$, namely, replacing the model outputs $M(t)$ in Eq. (1) by the adjusted model outputs $\tilde{M}(t)$ in Eq. (3).

We can now compare the results of the first regression for the raw model in Table 4, and the adjusted model in Table 6, for the period 1996-2003. In Table 6, the numbers $c$ and $a$ are respectively closer to 0 and 1 than in Table 4 . The adjusted model does an appreciably better job at characterizing the the evolution of total column ozone. Specifically, except for the $0-10^{\circ} \mathrm{N}$ band, $\mathrm{c}$ is never significant and $a$ is very close to 1 across all latitudes. The fit is dramatically improved for the adjusted model: the RSE is always smaller. Indeed the last two columns of Table 6 report the RSE for the raw model (same as last column of Table 4), and the RSE for the adjusted model. The enhancement is larger with high latitude since ozone is less stable there than near the equator.
Table 4. Coefficients estimates from the first regression of the measurements on the model outputs, and Residual Standard Error over the period January 1996 to December 2003. A perfect match between the model and the measurements would yield $c=0$ and $a=1$ (Standard errors in parentheses).

\begin{tabular}{lcccc}
\hline Latitude & $\mathrm{c}$ & $\mathrm{a}$ & $\rho$ & $\mathrm{RSE}$ \\
\hline $60-50^{\circ} \mathrm{S}$ & $\mathbf{1 0 1 . 8}(22.6)$ & $\mathbf{0 . 6 3}(0.07)$ & $0.65(0.08)$ & 9.2 \\
$50-40^{\circ} \mathrm{S}$ & $-28.6(17.1)$ & $1.05(0.05)$ & $0.74(0.08)$ & 5.7 \\
$40-30^{\circ} \mathrm{S}$ & $\mathbf{- 1 0 3 . 6 ( 2 1 . 4 )}$ & $\mathbf{1 . 3 2}(0.07)$ & $0.75(0.08)$ & 4.6 \\
$30-20^{\circ} \mathrm{S}$ & $\mathbf{6 0 . 2}(25.0)$ & $\mathbf{0 . 7 6}(0.09)$ & $0.79(0.06)$ & 5.3 \\
$20-10^{\circ} \mathrm{S}$ & $\mathbf{9 8 . 2}(21.5)$ & $\mathbf{0 . 6 2}(0.08)$ & $0.77(0.07)$ & 3.6 \\
$10-0^{\circ} \mathrm{S}$ & $\mathbf{9 2 . 3}(18.8)$ & $\mathbf{0 . 6 5}(0.07)$ & $0.89(0.05)$ & 2.8 \\
$0-10^{\circ} \mathrm{N}$ & $14.3(18.6)$ & $0.95(0.07)$ & $0.89(0.05)$ & 2.7 \\
$10-20^{\circ} \mathrm{N}$ & $-3.0(21.7)$ & $1.00(0.08)$ & $0.82(0.07)$ & 4.3 \\
$20-30^{\circ} \mathrm{N}$ & $-0.7(19.3)$ & $0.99(0.07)$ & $0.81(0.06)$ & 4.7 \\
$30-40^{\circ} \mathrm{N}$ & $\mathbf{9 9 . 9}(23.6)$ & $\mathbf{0 . 6 4}(0.08)$ & $0.82(0.07)$ & 6.9 \\
$40-50^{\circ} \mathrm{N}$ & $45.8(46.4)$ & $0.85(0.14)$ & $0.79(0.09)$ & 11.1 \\
$50-60^{\circ} \mathrm{N}$ & $-22.0(50.9)$ & $1.02(0.14)$ & $0.76(0.12)$ & 11.6 \\
\hline
\end{tabular}

For further demonstration, Fig. 4 displays for the period 1996-2003, the measurements (in black), the UIUC 2-D model outputs (in red) and the adjusted model outputs (in green) for $60-50^{\circ} \mathrm{S}, 50-40^{\circ} \mathrm{S}$, and Fig. 5 shows similar comparison for $40-50^{\circ} \mathrm{N}$ and $50-60^{\circ} \mathrm{N}$. In each case the adjusted model is seen to be much closer to the observations. The minimum values are very well predicted, and the maximum values are well predicted. Furthermore, for $60-50^{\circ} \mathrm{S}$, the currently limited understanding of the polar vortex does not enable the adjusted model to completely capture the variations. In particular, the abrupt changes occurring during the months ranging from January to April are well beyond predictability without further meteorology inputs. For the other latitudes, the correspondence between observed data and adjusted model outputs is excellent, pointing out the strength of the method.

Note that Butchart et al. (2003) presented a coupled chemistry-transport model which simulates the QBO. The induced total column ozone at the equator was well reproduced. However, the sub-tropical QBO-induced signal in total column ozone was not adequately represented, especially in terms of frequency. The numerical simulation of the QBO is still a challenging problem and the statistical approach is a simple and effective method.

Finally, Fig. 6a displays the estimates of the indicators of the months obtained from the second regression, for the period 1996-2003 based on the UIUC 2-D model and the corresponding results using adjusted model outputs are shown in Fig. 6b. Note that we did not correct for a trend anomaly since the trends were never deemed significant in the first time period 1979-1995 (Table 5). Both the number and the levels of the monthly anomalies dropped off drastically. 
Table 5. Coefficients estimates of the second regression (Eq. 2) based on regressing the residuals from the first regression on the solar flux ( $b$ in DU per 100 flux), the trend ( $\omega_{1}$ in DU per decade), the AAO (South) or the AO (North) ( $c_{a o}$ per 10 units of either $700 \mathrm{hPa}$ height anomalies poleward of $20^{\circ} \mathrm{S}$ or $1000 \mathrm{hPa}$ height anomalies poleward of $20^{\circ} \mathrm{N}$ on their respective loading patterns), the QBO ( $c_{q b o}$ per 10 units of $50 \mathrm{hPa}$ zonal wind index) with its sine $\left(c_{q b o s}\right)$ and cosine $\left(c_{q b o c}\right)$ multiples, and the indicators of the months (not displayed here) over the period January 1979 to December 1995. An insignificant coefficient means no model anomaly for the related regressor (Standard errors in parentheses).

\begin{tabular}{lcccccc}
\hline Latitude & $b$ (solar) & $\omega_{1}$ (trend) & $c_{a o}$ & $c_{q b o}$ & $c_{q b o s}$ & $c_{q b o c}$ \\
\hline $60-50^{\circ} \mathrm{S}$ & $0.16(0.92)$ & $-0.36(1.02)$ & $-0.27(0.47)$ & $0.16(0.77)$ & $-1.83(1.06)$ & $1.51(1.04)$ \\
$50-40^{\circ} \mathrm{S}$ & $-1.08(0.67)$ & $0.66(0.74)$ & $-\mathbf{1 . 0 3}(0.34)$ & $\mathbf{2 . 0 1}(0.56)$ & $-\mathbf{1 . 9 9}(0.74)$ & $-\mathbf{1 . 8 6}(0.78)$ \\
$40-30^{\circ} \mathrm{S}$ & $-0.72(0.41)$ & $0.23(0.45)$ & $-0.11(0.21)$ & $\mathbf{1 . 8 6}(0.34)$ & $-\mathbf{1 . 7 3}(0.47)$ & $-\mathbf{2 . 5 9}(0.45)$ \\
$30-20^{\circ} \mathrm{S}$ & $0.47(0.34)$ & $-0.49(0.38)$ & $0.11(0.18)$ & $\mathbf{1 . 4 7}(0.29)$ & $-\mathbf{0 . 8 0}(0.39)$ & $-\mathbf{2 . 4 9}(0.38)$ \\
$20-10^{\circ} \mathrm{S}$ & $0.41(0.29)$ & $-0.49(0.32)$ & $0.12(0.15)$ & $\mathbf{0 . 8 3}(0.24)$ & $-0.19(0.32)$ & $-\mathbf{1 . 9 0}(0.34)$ \\
$10-0^{\circ} \mathrm{S}$ & $0.02(0.30)$ & $0.14(0.33)$ & $-0.13(0.15)$ & $-\mathbf{1 . 3 6}(0.25)$ & $0.28(0.34)$ & $-0.07(0.33)$ \\
$0-10^{\circ} \mathrm{N}$ & $-0.14(0.31)$ & $0.37(0.35)$ & $0.14(0.16)$ & $\mathbf{1 . 5 4}(0.25)$ & $-0.40(0.35)$ & $0.06(0.34)$ \\
$10-20^{\circ} \mathrm{N}$ & $-0.37(0.34)$ & $-0.08(0.38)$ & $\mathbf{0 . 4 7}(0.18)$ & $\mathbf{0 . 5 8}(0.27)$ & $-0.05(0.36)$ & $\mathbf{1 . 3 8}(0.38)$ \\
$20-30^{\circ} \mathrm{N}$ & $-0.20(0.38)$ & $-0.23(0.42)$ & $\mathbf{0 . 5 4}(0.20)$ & $\mathbf{1 . 2 9}(0.30)$ & $0.22(0.42)$ & $\mathbf{2 . 1 1}(0.41)$ \\
$30-40^{\circ} \mathrm{N}$ & $0.12(0.49)$ & $-0.29(0.55)$ & $-\mathbf{0 . 6 7}(0.26)$ & $\mathbf{1 . 0 4}(0.39)$ & $0.43(0.55)$ & $\mathbf{2 . 2 3}(0.53)$ \\
$40-50^{\circ} \mathrm{N}$ & $-0.26(0.67)$ & $0.25(0.76)$ & $\mathbf{- 2 . 8 0}(0.35)$ & $0.61(0.55)$ & $0.60(0.73)$ & $1.01(0.77)$ \\
$50-60^{\circ} \mathrm{N}$ & $-0.84(0.88)$ & $0.09(0.99)$ & $\mathbf{- 1 . 8 1}(0.46)$ & $1.09(0.72)$ & $1.11(0.99)$ & $1.44(0.96)$ \\
\hline
\end{tabular}

Table 6. Coefficients estimates from the first regression of the measurements on the statistically adjusted model outputs, and Residual Standard Error. The RSE for the unadjusted model outputs (from Table 4) is shown in the last column for comparison purposes. January 1996 to December 2003. A perfect match between the model and the measurements would yield $c=0$ and $a=1$ (Standard errors in parentheses).

\begin{tabular}{lccccc}
\hline Latitude & $\mathrm{c}$ & $\mathrm{a}$ & $\rho$ & RSE & RSE (no adjustement) \\
\hline $60-50^{\circ} \mathrm{S}$ & $30.4(16.8)$ & $\mathbf{0 . 8 9}(0.05)$ & $0.69(0.08)$ & 6.2 & 9.2 \\
$50-40^{\circ} \mathrm{S}$ & $2.7(11.7)$ & $0.99(0.04)$ & $0.74(0.07)$ & 4.8 & 5.7 \\
$40-30^{\circ} \mathrm{S}$ & $-7.2(10.1)$ & $1.02(0.03)$ & $0.78(0.06)$ & 3.4 & 4.6 \\
$30-20^{\circ} \mathrm{S}$ & $-14.9(10.5)$ & $1.04(0.04)$ & $0.79(0.06)$ & 2.3 & 5.3 \\
$20-10^{\circ} \mathrm{S}$ & $-21.5(13.6)$ & $1.07(0.05)$ & $0.80(0.06)$ & 1.9 & 3.6 \\
$10-0^{\circ} \mathrm{S}$ & $-8.2(17.7)$ & $1.04(0.07)$ & $0.90(0.05)$ & 2.0 & 2.8 \\
$0-10^{\circ} \mathrm{N}$ & $\mathbf{2 5 . 0 ( 1 1 . 8 )}$ & $\mathbf{0 . 9 2}(0.04)$ & $0.88(0.05)$ & 2.0 & 2.7 \\
$10-20^{\circ} \mathrm{N}$ & $4.0(8.1)$ & $0.99(0.03)$ & $0.75(0.07)$ & 2.1 & 4.3 \\
$20-30^{\circ} \mathrm{N}$ & $-5.3(8.6)$ & $1.01(0.03)$ & $0.73(0.07)$ & 2.5 & 4.7 \\
$30-40^{\circ} \mathrm{N}$ & $12.3(12.6)$ & $0.94(0.04)$ & $0.80(0.06)$ & 3.8 & 6.9 \\
$40-50^{\circ} \mathrm{N}$ & $11.8(9.8)$ & $0.96(0.03)$ & $0.68(0.07)$ & 4.5 & 11.1 \\
$50-60^{\circ} \mathrm{N}$ & $1.9(10.4)$ & $0.99(0.03)$ & $0.59(0.08)$ & 5.9 & 11.6 \\
\hline
\end{tabular}

However, some monthly anomalies are still present, even accounting for the QBO and AO. Across all latitudes, the statistically adjusted model shows no anomalies from July to October.

\section{Conclusions}

In this paper, we have proposed a novel method to estimate deficiencies and modify chemistry-transport model calculations for total column ozone. The main advantage of our method is to combine the detection of deficiencies involving processes not captured by the model (e.g. QBO, AAO, $\mathrm{AO}, .$. ) and captured by the model (annual cycle, solar cy- cle,..). What is gained through this method is the possibility of detecting deficiencies and improving predictions, not yet attributing deficiencies to specific processes. We adjusted the model outputs to gain some improvement in the quality of the prediction. The results show that for the period from 1996 to 2003, the improvement of the prediction is appreciable. The purpose is different from data assimilation (Douglass et al., 1996; Levelt et al., 1998; Smyshlyaev and Geller, 2001; Khattatov et al., 2000; Fierli et al., 2002). Specifically, we do not modify the model itself, but we correct the model outputs. This method could potentially be used for 3-D models, or in other fields such as climate prediction with General Circulation Models (GCM). 
Another advantage of our diagnostic and correction approach has to do with ozone trends assessment. With our technique, we lessen the shift, scale and monthly anomalies, and improve the representation of the $\mathrm{AAO} / \mathrm{AO}$ and the QBO. For the solar cycle, AAO/AO and the QBO, we must rely on scenarios for these variations, since our method uses observations of some proxies, as it has already been done for the solar cycle in the UIUC 2-D model over the period 19792050. Under a specific scenario, the trends can be computed. Note that short-term variations linked to the AAO/AO and the QBO may have a significant impact on trends for time periods of 10 years or so, but not so much for 50 years or so. Therefore, our method has some predictive power concerning the trends. This would be helpful to account for these effects, especially under a scenario with a change in the AO index due to greenhouse-gas forcing (Shindell et al., 1999), that could trigger a trend in ozone. A future work would be to make improvements in future long term trends, by carrying out a similar diagnostics and correction procedure to 3D model outputs for halogen trends and chemistry-dynamics coupling. Indeed, if some deficiencies can be identified for the proxies associated with the emissions, the temperatures, or the treatment of the dynamics, the correction will have a beneficial effect. Note that the degree of uncertainty in a combined model - statistics prediction will also depend on the quality of the proxy predictions.

The failings in the 2-D dynamics are in the process of being diagnosed, but that it may be in part due to the $5^{\circ}$ horizontal resolution and the resulting effects of this coarse resolution on the dynamics. It is relatively easy to carry out the analysis and the correction and fast in terms of computation time. However, we do not intimately associate observed anomalies with the chemical reactions and the transport equations in the model. We a posteriori correct for it without learning about the model itself. Accordingly, a possible way to use our technique for this purpose would be to design an experiment where some inputs or constants fixed in the model could vary, and examine deficiencies of the model with our two stage procedure. This could probably give model developers some additional knowledge in order to scientifically improve the treatment of chemistry and transport processes.

Finally, our proposed method relies on two first-order approximations (with statistically estimated errors): a linear relation between the model outputs and the measurements, and between the lack of fit and the explanatory variables. Even though our technique was very effective, it may be possible to improve it by allowing non-linear connections or mixed effects. For instance, building a method that would include some realistic assumptions about the combined levels of chlorine and aerosols in the atmosphere. Indeed, Tie and Brasseur (1995) showed that the response of ozone to aerosols is negative when chlorine loadings are low, and positive when they are high. If a chemistry-transport model does not adequately replicate this feature, the associated anomaly would be better estimated with a non-linear model with mixed effects than a linear one assuming independent responses.

Acknowledgements. Although the research described herein has been funded by the United States Environmental Protection Agency through STAR Cooperative Agreement \#R-82940201-0 to the University of Chicago, it has not been subjected to the Agency's required peer and policy review and therefore does not necessarily reflect the views of the Agency, and no official endorsement should be inferred. The atmospheric modeling studies were supported in part by EPA's Global Programs Division and by the NASA ACMAP program. Finally, we wish to thank our late colleague G. C. Reinsel for his valuable comments which improved the quality of the paper.

Edited by: M. Dameris

\section{References}

Austin, J., Shindell, D., Beagley, S. R., Bruhl, C., Dameris, M., Manzini, E., Nagashima, T., Newman, P., Pawson, S., Pitari, G., Rozanov, E., Schnadt, C., and Shepherd, T. G.: Uncertainties and assessments of chemistry-climate models of the stratosphere, Atmos. Chem. Phys., 3, 1-27, 2003,

SRef-ID: 1680-7324/acp/2003-3-1.

Butchart, N., Scaife, A. A., Austin, J., Hare, S. H. E., and Knight, J. R.: Quasi-biennial oscillation in ozone in a coupled chemistry-climate model, J. Geophys. Res.-Atmos., 108, doi:10.1029/2002JD003004, 2003.

Choi, W.: On the meridional circulation in the transformed Eulerian mean system, J. Korean. Meteorol. Soc., 31, 325-337, 1995.

Choi, W. and Youn, D.: Effects of physical and numerical schemes on model-calculated ozone distribution in the stratosphere, J. Atmos. Sci., 3, 39-52, 2001.

Considine, D. B., Stolarski, R. S., Hollandsworth, S. M., Jackman, C. H., and Fleming, E. L.: A Monte Carlo uncertainty analysis of ozone trend predictions in a two-dimensional model, J. Geophys. Res.-Atmos., 104, 1749-1765, 1999.

Dameris, M., Grewe, V., Ponater, M., Deckert, R., Eyring, V., Mager, F., Matthes, S., Schnadt, C., Stenke, A., Steil, B., Bruhl, C., and Giorgetta, M. A.: Long-term changes and variability in a transient simulation with a chemistry-climate model employing realistic forcing, Atmos. Chem. Phys., 5, 2121-2145, 2005,

SRef-ID: 1680-7324/acp/2005-5-2121.

DeMore, W. B., Sander, S., Golden, D., Hampson, R., Kurylo, M., Howard, C., Ravishankara, A., Kolb, C., and Molina, M.: Chemical Kinetics and Photochemical Data for Use in Stratospheric Modeling, Evaluation Number 12, Tech. Rep., 97-4, NASA/JPL Publication, 1997.

Douglass, A. R., Weaver, C. J., Rood, R. B., and Coy, L.: A threedimensional simulation of the ozone annual cycle using winds from a data assimilation system, J. Geophys. Res.-Atmos., 101, 1463-1474, 1996.

Douglass, A. R., Prather, M. J., Hall, T. M., Strahan, S. E., Rasch, P. J., Sparling, L. C., Coy, L., and Rodriguez, J. M.: Choosing meteorological input for the global modeling initiative assessment of high-speed aircraft, J. Geophys. Res.-Atmos., 104, 27 545-27 564, 1999. 
Fierli, F., Hauchecorne, A., Bekki, S., Theodore, B., and d'Andon, O. F.: Data assimilation of stratospheric ozone using a high-resolution transport model, Geophys. Res. Lett., 29, doi:10.1029/2001GL014272, 2002.

Fioletov, V. E., Bodeker, G. E., Miller, A. J., McPeters, R. D., and Stolarski, R.: Global and zonal total ozone variations estimated from ground-based and satellite measurements: 1964-2000, J. Geophys. Res.-Atmos., 107, doi:10.1029/2001JD001350, 2002.

Fish, D. J. and Burton, M. R.: The effect of uncertainties in kinetic and photochemical data on model predictions of stratospheric ozone depletion, J. Geophys. Res.-Atmos., 102, 25 537-25 542, 1997.

Hall, T. M. and Plumb, R. A.: Age as a diagnostic of stratospheric transport, J. Geophys. Res.-Atmos., 99, 1059-1070, 1994.

Hall, T. M., Waugh, D. W., Boering, K. A., and Plumb, R. A.: Evaluation of transport in stratospheric models, J. Geophys. Res.Atmos., 104, 18 815-18 839, 1999.

Hein, R., Dameris, M., Schnadt, C., Land, C., Grewe, V., Kohler, I., Ponater, M., Sausen, R., Steil, B., Landgraf, J., and Bruhl, C.: Results of an interactively coupled atmospheric chemistry general circulation model: Comparison with observations, Ann. Geophys., 19, 435-457, 2001,

\section{SRef-ID: 1432-0576/ag/2001-19-435.}

Khattatov, B. V., Lamarque, J. F., Lyjak, L. V., Menard, R., Levelt, P., Tie, X. X., Brasseur, G. P., and Gille, J. C.: Assimilation of satellite observations of long-lived chemical species in global chemistry transport models, J. Geophys. Res.-Atmos., 105, 29 135-29 144, 2000.

Kim, J. K.: Parameterization of land surface processes in an atmospheric general circulation model, $\mathrm{PhD}$ thesis, Seoul National University, 178 pp., 1999.

Langner, J., Rodhe, H., and Olofsson, M.: Parameterization of subgrid scale vertical tracer transport in a global 2-dimensional model of the troposphere, J. Geophys. Res.-Atmos., 95, 13691$13706,1990$.

Lean, J. L., Rottman, G. J., Kyle, H. L., Woods, T. N., Hickey, J. R., and Puga, L. C.: Detection and parameterization of variations in solar mid- and near-ultraviolet radiation (200-400 nm), J. Geophys. Res.-Atmos., 102, 29 939-29 956, 1997.

Levelt, P. F., Khattatov, B. V., Gille, J. C., Brasseur, G. P., Tie, X. X., and Waters, J. W.: Assimilation of MLS ozone measurements in the global three-dimensional chemistry transport model ROSE, Geophys. Res. Lett., 25, 4493-4496, 1998.

Miller, A. J., Nagatani, R. M., Flynn, L. E., Kondragunta, S., Beach, E., Stolarski, R., McPeters, R. D., Bhartia, P. K., DeLand, M. T., Jackman, C. H., Wuebbles, D. J., Patten, K. O., and Cebula, R. P.: A cohesive total ozone data set from the SBUV(/2) satellite system, J. Geophys. Res.-Atmos., 107, 4701, doi:10.1029/2001JD000853, 2002.

Park, J. H., Ko, M. K. W., Jackman, C. H., Plumb, R. A., and Sage, K. H. E.: Models and Measurements II., Tech. rep., NASA Langley Research Center, Hampton, VA, 496 pp., 1999.

Randel, W. J. and Cobb, J. B.: Coherent variations of monthly mean total ozone and lower stratospheric temperature, J. Geophys. Res., 99(D3), 5433-5448, doi:10.1029/93JD05454, 1994.

Reinsel, G., Tiao, G. C., Wang, M. N., Lewis, R., and Nychka, D.: Statistical-analysis of stratospheric ozone data for the detection of trends, Atmos. Environ., 15, 1569-1577, 1981.

Reinsel, G. C.: Trend analysis of upper stratospheric Umkehr ozone data for evidence of turnaround, Geophys. Res. Lett., 29, doi:10.1029/2002GL01471, 2002.

Sander, S. P., Friedl, R. R. DeMore, W. B., Golden, D. M., Kurylo, M. J., Hampson, R. F., Huie, R. E., Moortgat, G. K., Ravishankara, A. R., Kolb, C. E., and Molina, M. J.: Chemical Kinetics and Photochemical Data for Use in Stratospheric Modeling, Supplement to Evaluation 12: Update of Key Reactions, Tech. Rep. 00-3, NASA/JPL Publication, Pasadena, California, 2000.

Shindell, D. T., Miller, R. L., Schmidt, G. A., and Pandolfo, L.: Simulation of recent northern winter climate trends by greenhouse-gas forcing, Nature, 399, 452-455, 1999.

Smyshlyaev, S. P. and Geller, M. A.: Analysis of SAGE II observations using data assimilation by the SUNY-SPB two-dimensional model and comparison to TOMS data, J. Geophys. Res.-Atmos., 106, 32 327-32 335, 2001.

Solomon, S., Portmann, R. W., Garcia, R. R., Thomason, L. W., Poole, L. R., and McCormick, M. P.: The role of aerosol variations in anthropogenic ozone depletion at northern midlatitudes, J. Geophys. Res.-Atmos., 101, 6713-6727, 1996.

Stewart, G. W.: Collinearity and least squares regression, With discussion, Statist. Sci., 2, 68-100, 1987.

Thomason, L. W., Poole, L. R., and Deshler, T.: A global climatology of stratospheric aerosol surface area density deduced from stratospheric aerosol and gas experiment II measurements: 1984-1994, J. Geophys. Res.-Atmos., 102, 8967-8976, 1997.

Thompson, D. W. J. and Wallace, J. M.: Annular Modes in the Extratropical Circulation. Part I: Month-to-Month Variability, J. Climate, 13, 1000-1016, 2000.

Tiao, G. C., Reinsel, G. C., Xu, D. M., Pedrick, J. H., Zhu, X. D., Miller, A. J., Deluisi, J. J., Mateer, C. L., and Wuebbles, D. J.: Effects of autocorrelation and temporal sampling schemes on estimates of trend and spatial correlation, J. Geophys. Res.-Atmos., 95, 20 507-20 517, 1990.

Tie, X. X. and Brasseur, G.: The response of stratospheric ozone to volcanic-eruptions - sensitivity to atmospheric chlorine loading, Geophys. Res. Lett., 22, 3035-3038, 1995.

Weatherhead, E. C., Reinsel, G. C., Tiao, G. C., Meng, X. L., Choi, D. S., Cheang, W. K., Keller, T., DeLuisi, J., Wuebbles, D. J., Kerr, J. B., Miller, A. J., Oltmans, S. J., and Frederick, J. E.: Factors affecting the detection of trends: Statistical considerations and applications to environmental data, J. Geophys. Res.Atmos., 103, 17 149-17 161, 1998.

Wei, C. F., Larson, S. M., Patten, K. O., and Wuebbles, D. J.: Modeling of ozone reactions on aircraft-related soot in the upper troposphere and lower stratosphere, Atmos. Environ., 35, 61676180, 2001.

WMO: Scientific Assessment of Ozone Depletion, Tech. Rep. 14, World Meteorological Organisation, Global Ozone Res. and Monit. Proj., Geneva, 2003.

Wuebbles, D. J., Patten, K. O., Johnson, M. T., and Kotamarthi, R.: New methodology for Ozone Depletion Potentials of short-lived compounds: n-propyl bromide as an example, J. Geophys. Res.Atmos., 106, 14 551-14 571, 2001.

Zerefos, C. S., Bais, A. F., Ziomas, I. C., and Bojkov, R. D.: On the relative importance of quasi-biennial oscillation and el-nino southern oscillation in the revised dobson total ozone records, J. Geophys. Res.-Atmos., 97, 10 135-10 144, 1992. 